SHORT REPORT

\title{
Building camps and work related injuries
}

F Tüchsen, H Hannerz

Occup Environ Med 2004;61:370-371. doi: 10.1136/oem.2002.006783

\begin{abstract}
Aims: To focus on one possible predictor of reported work related injuries-the role of living in building-site camps versus daily commuting from home to construction sites. Methods: A cohort of construction workers was collected, based on personnel files from contractors involved in the building of the Great Belt Bridge. The files included information on employment periods and whether or not the employees lived in building-site camps. The cohort was followed up for injuries reported to the National Work Environment Authority.

Results: Construction workers living in camps reported 217 accidents, of which 24 were serious or fatal. Among those not living in camps we found 262 accidents, of which 29 were serious or fatal. The relative risk for all accidents for camp versus non-camp was 0.84 (95\% $\mathrm{Cl} 0.69$ to 1.00). The respective figure for serious or fatal accidents was $R R=0.85$ (95\% Cl 0.47 to 1.52 ).

Conclusion: Results suggest that high accident rates at large construction sites may be reduced, if commuting is replaced by living on-site.
\end{abstract}

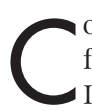
onstruction machinery operators in Finland have been found to be at high risk for hospitalising back injuries. ${ }^{1}$ In Denmark, working in the construction industry is one of the most risky jobs in terms of hospitalising work accidents. ${ }^{2}$ Out of 49 industries the building and construction industry was associated with the highest standardised hospitalisation ratios for injuries of the back, the trunk, and lower extremities. ${ }^{2}$ The construction of the Great Belt suspension bridge was no exception and all the experience gained on that project should in our view be applied for the prevention of future accidents. Due to the long hours worked every day, the question of restitution is important. Most of the workers had a 12 hour workday and a seven day long spell of work followed by seven days off-duty. The daily boat connection was 630 am and $7 \mathrm{pm}$ for the day shift and $630 \mathrm{pm}$ and 7 am for the night shift. In the present analysis we focus on one aspect: the role of living in building-site camps versus daily commuting from home to site. Pekkarinen and Anttonen compared accidents during a construction project in a remote area in the former Soviet Union from 1977 to 1985 with Finish construction activities. The high accident rate could be due to disorders in the working environment as a result of language related communication difficulties. The workforce was unstable, and conditions such as lack of natural light had a negative effect, especially during autumn. ${ }^{3}$

Many large scale construction projects, such as the Danish bridges, take place in less populated areas, where hundreds or thousands of workers are recruited for a limited time and therefore usually have their homes far away from the construction sites. Temporary building camps are usually established in connection with such construction projects. In the analysed project, half of the employees lived in camps during the construction period, while the others chose to commute long distances every day.

The camps were located close to the building sites and a few kilometres from small towns with 10 000-15000 inhabitants. They consisted of small two-storied lodgings in standard ship containers and a place where workers could place their own caravan. The employer did not regulate the off-duty hours in the camps in any way. Kitchen and laundry facilities were provided, and the workers did the cooking. A local grocer had an outlet in the camp area and accepted orders for later delivery in the outlet. The workers were free to leave camp during off-duty hours to go elsewhere for recreational activities, but most of the workers wanted to work as much as possible while they were there and have long spells in between with their families.

The Great Belt Fixed Link consists of a suspension bridge for cars, a tunnel for trains, two parallel low level bridges, and a partially artificial island. The Great Belt Bridge is the world's second longest suspension bridge, with a span of 1624 metres-only exceeded by the Japanese Akashi-Kaikyo Bridge. The pylons are 254 metres high, and the bridge sections are placed 75 metres above sea level. Each bridge section weighs 1000 tons, and the 2.7 kilometres of road between the two anchors is assembled from 57 such bridge sections.

The aim of the present study was to estimate the possible effect on lost days injuries of living in building-site camps versus daily commuting from home to construction site.

\section{METHODS}

The identification of workers was based on company files, as was the information on living in the building camps. We used the unique personal identification number to link information about employment spells for each worker into a work history for 1987 men hired one or more times by various Great Belt contractors. Most of these contractors were ad hoc established by a group of building contractors.

In Denmark injuries occurring during working hours are reportable after one day's absence more than the day of the accident. ${ }^{4}$ It means that accidents happening during commuting between home and site are not reportable in Denmark and therefore not included in the present study. The reports are filed in a national register, which was searched for all reported injuries. Fatal injuries include death due to an accident at work within a year after the event, and serious accidents are defined by a list of traumas.

The National Work Environment Authority established special local units during the construction period, and an occupational health nurse was hired to take care of injuries and report them. It is therefore believed that the rate and reliability of reporting was higher than in many other projects, but the underreporting is unknown (S Spangenberg, personal communication, 2002).

For each of the 1987 individuals, we calculated personyears at risk by calendar year and age from exact dates of employment and exact dates of departure from the firm. We 
Main messages

- Those living in building-site camps suffered fewer injuries during work than those commuting daily.

used log-linear Poisson regression to estimate the relative risk for injury at work between people living at home and people living in building camps. The calculations were based on 2291 person-years at risk, of which the commuters accounted for 1142 years and those living in building camps accounted for 1149 years at risk. In the analyses we controlled for calendar year $(1992,1993,1994,1995)$ and age category (18-29, 30$39,40-49, \geqslant 50$ years).

\section{RESULTS}

Approximately half of the workers lived in building camps. Altogether those living in camps experienced 217 reported accidents, of which 24 were serious or fatal. Among those not living in camps we found 262 accidents, of which 29 were serious or fatal. The relative risk for all accidents for camp/ non-camp was 0.84 (95\% CI 0.69 to 1.00$)$. The respective figures for serious or fatal accidents were RR $=0.85$ (95\% CI 0.47 to 1.52 ).

\section{DISCUSSION}

We found a lower relative risk for all accidents and a similar tendency for serious accidents among the workers living in building camps.

The interpretation of reported accidents is only valid when underreporting is fully controlled, because the missing fraction varies from one industry or firm to another, as well as over time. As all injury reports in the present study came from the same consortium, a difference between the reported injuries among those living in camps and those commuting is unlikely. The underreporting of the consortium is unknown. The relative risk therefore is likely to be more accurate than the injury rates. Another possible confounding factor might be that the two groups of workers are different in other aspects too such as age, marital status, and risk taking behaviour. We have no such information about the Great Belt workers, but the workers at Copenhagen Metro, of which many had also been employed at Great Belt, were interviewed recently. ${ }^{5}$ There were no differences between commuters and workers living in building camps in the proportion who have a spouse $(68 \%)$. Assuming the groups are comparable, the most likely explanation for the difference in accident rates is the difference in recreation and sleep. The commuters in the Copenhagen Metro project sleep on average one hour less than those living in camps. Furthermore, of those working long hours, only $3 \%$ of those commuting 100 kilometres or more felt that they had an opportunity for recreation after work. Those living in camps reported that they felt rested after work much more often (OR $=7.6 ; 95 \%$ CI 2.3 to 24.6$).^{5}$ Hännecke et al suggest that accidents increase exponentially after the ninth hour. ${ }^{6}$ This may explain the general high rate in both groups. The difference between them is, however, more likely caused by insufficient recuperation.

When the more recent Øresund Link project was planned it was known that the injury rates at the Great Belt Link were high. In the beginning of the Øresund Link project construction period, the injury rates were also high, but then a large scale safety campaign was successfully implemented. ${ }^{7}$ After that the injury rates were only half those seen on the present project, but more thorough analyses like those presented here might have provided evidence for even better results.

\section{Policy implications}

- The accident rate might be reduced if it becomes relatively more attractive to live in building-site camps compared to commuting every day.

A report from 1969 suggested that American construction workers who had many traffic accidents also had many accidents at work and suggested that it may be possible to predict accidents by analysing workers' attitudes expressed in questionnaires. ${ }^{8}$ We had no data concerning traffic accidents. As those living in camps spend very little time in the traffic compared to the commuters it is, however, likely that analysis including both lost time accidents and traffic accidents will show a bigger difference in favour of the building camps.

Our results are of borderline significance. The large potential for prevention suggested by the results should encourage other researchers to carry out further analysis in other data sets in order to get safer estimates.

\section{Conclusion}

Our results suggest that the high injury rate at large construction projects may be reduced if commuting is replaced by living in camps.

\section{ACKNOWLEDGEMENTS}

Financial support for the present study came from a special bill "satspuljen 1999, pkt. 6", from Folketinget, The Danish Parliament: account FS 17.21.05.30. Contractors were CASA (Centre for Alternative Social Analysis) and Carl Bro A/S. The National Institute of Social Research (SFIsurvey) collected the data. We are indebted to the various Great Belt contractors for providing employment information for our study. The National Work Environment Authority provided data regarding reported injuries.

\section{Authors' affiliations \\ F Tüchsen, H Hannerz, National Institute of Occupational Health, Copenhagen, Denmark}

Correspondence to: Dr F Tüchsen, National Institute of Occupational Health, Lersø Parkallé 105, DK-2100 Copenhagen $\varnothing$, Denmark; fH@ami.dk

Accepted 28 May 2003

\section{REFERENCES}

1 Leino-Arjas P, Kaila-Kangas L, Keskimaki I, et al. Inpatient hospital care for lumbar intervertebral disc disorders in Finland in relation to education, occupational class, income, and employment. Public Health 2002;1 16:272-8.

2 Baarts C, Mikkelsen KL, Hannerz H, et al. Use of a national hospitalization register to identify industrial sectors carrying high risk of severe accidents. A three-year cohort study of more than 900,000 Danish men. Am J Ind Med 2000;38:619-27.

3 Pekkarinen A, Anttonen $\mathrm{H}$. The comparison of accidents in a foreign construction project with construction in Finland. Journal of Safety Research 1989;20:187-95.

4 Jørgensen K. The functions of the Danish Registry of Occupational Injuries. Occupational accidents and diseases. Copenhagen: The Danish Labour Inspection Service, 1991.

5 Mathiesen K, Fløe T, Brendstrup T, et al. Arbejdsmiljø, helbred og camps. Afsluttende rapport. København: Carl Bro A/S, CASA, 2003.

6 Hänecke K, Tiedemann S, Nachreiner F, et al. Accident risk as a function of hour at work and time of day as determined from accident data and exposure models for the German working population. Scand J Work Environ Health 1998;24(suppl 3):43-8.

7 Spangenberg $\mathrm{S}$, Mikkelsen $\mathrm{KL}$, Kines $\mathrm{P}$, et al. The construction of the Øresund link between Denmark and Sweden: the effect of a multifaceted safety campaign. Safety Science 2002;40:457-65.

8 de Stwolinski LW. A survey of the safety environment of the construction industry. Palo Alto, CA: Stanford University, 1969. 